\title{
Os sinais de nome atribuídos no contexto acadêmico: uma abordagem Antroponomástica
}

\section{The name signs attributed in the academic context: an Anthroponomical approach}

Gabriele Cristine Rech

Universidade Estadual de Mato Grosso do Sul (UEMS)

Doutoranda do Programa de Pós-Graduação em Letras da Unioeste

https://orcid.org/0000-0003-2470-3416

gabinhails@gmail.com

Fabíola Sucupira Ferreira Sell

Universidade do Estado de Santa Catarina (UDESC)

Mestrado Profissional em Ensino de Ciências, Matemática e Tecnologias

https://orcid.org/0000-0002-2315-7073

\section{Resumo}

Este trabalho faz parte do projeto de pesquisa em andamento denominado "Estudos Onomásticos da Língua Brasileira de Sinais", e tem por objetivo analisar a atribuição de um sinal de nome para alguns autores/pesquisadores, cujos sinais de nome foram pesquisados no Manuário Acadêmico e Escolar elaborado pelo Instituto Nacional de Educação de Surdos. Tal pesquisa se insere nos estudos onomásticos das línguas de sinais, uma vez que em muitas comunidades de línguas de sinais, é comum a atribuição de um sinal para que o indivíduo possa ser reconhecido como integrante daquele grupo. Estes signos, que denominamos "sinais de nome", utilizam-se de características visuais, e são sempre motivados. Salienta-se que sinais de nome também são atribuídos para pessoas que não fazem parte da comunidade surda, mas que precisam ser referenciados constantemente, como é o caso de pesquisadores, autores, filósofos etc., relacionados ao ambiente acadêmico. Para tal análise, utilizamos a taxonomia proposta por Barros (2018), a qual identificou quatro principais taxes para classificar um sinal de nome: Empréstimo da Língua oral, Aspecto físico, Aspecto Comportamental e Aspecto Social. Como resultados preliminares podemos observar que a maioria das atribuições de sinais se relacionam a características físicas dos nomeados e pouco se relacionam com suas atuações profissionais.

Palavras-chave: Língua de sinais; Antroponomástica; Sinais de nome.

\section{Abstract}

This work is part of the ongoing research project called "Brazilian Sign Language Onomastic Studies", and its purpose is to analyze the assignment of a name sign to some authors/researchers, whose name signs were searched in the Manuário Acadêmico e Escolar prepared by the National Institute of Deaf Education. Such research is part of the onomastic 
studies of sign languages, since in many sign language communities, it is common to assign a sign so that the individual can be recognized as part of that group. This sign, called "name signs", uses visual characteristics and is always motivated. It is noted that name signs are also assigned to people who are not part of the deaf community, but who need to be constantly referenced, such as researchers, authors, philosophers, etc., related to the academic environment. For such analysis, we will use the taxonomy proposed by Barros (2018), which identified four main taxes to classify a name sign: Oral language loan, Physical appearance, Behavioral aspect and Social aspect. As preliminary results, we can observe that most of the signal assignments are related to physical characteristics of the nominees and little to their professional performance.

Keywords: Sign language; Anthroponomastics; Name signs.

A Onomástica é o ramo da Lexicologia que se ocupa em estudar os nomes próprios. Ela é dividida em duas principais áreas ${ }^{1}$ : Antroponomástica ${ }^{2}$ e toponomástica. A primeira, estuda os nomes das pessoas: nomes próprios individuais, sobrenomes, alcunhas e apelidos; a segunda estuda os nomes próprios de lugares, ou seja, os topônimos (SEABRA \& ISQUERDO, 2018: 993).

Segundo Dick (1992), o primeiro a utilizar o termo "Antroponímia" foi o filólogo português Leite de Vasconcelos, em 1887, que considerava a disciplina importante como um "excelente meio para conhecer os usos e costumes dos povos" (DICK, 1992: 178). Na mesma direção, Seabra \& Isquerdo afirmam que os topônimos e antropônimos "são produtos de um sistema de denominação que reflete o modo de viver de uma cultura e a maneira desta representar seus valores" (SEABRA \& ISQUERDO, 2018: 994)

\footnotetext{
${ }^{1}$ Amaral (2011, p.63) afirma que "os nomes próprios são uma classe bastante heterogênea de itens nominais e, por esse motivo, existem várias tentativas de classificá-los”. Neste sentido, o autor aponta que, além de nomes de pessoas e lugares, são considerados nomes próprios os nomes de organizações sociais, marcas, títulos de obras, etc.

${ }^{2}$ Segundo Seide (2016), a terminologia para designar o objeto de estudo e a disciplina não está padronizado. Muitos autores usam o termo antroponímia para os dois conceitos, entretanto, o Conselho Internacional de Ciências Onomásticas, propôs a diferenciação. Neste artigo adotaremos o termo antroponímia para um conjunto de nomes e Antroponomástica para a ciência que os estuda (Frai, 2016, p.91).
} 
As pessoas surdas, por meio das línguas de sinais, também nomeiam sujeitos que precisam ser identificados e referenciados, e para tal utilizam os sinais de nomes ${ }^{3}$, ou seja, signos criados a partir de elementos linguísticos e culturais que os constituem. Nesse sentido, esse artigo tem por objetivo analisar, a partir dos estudos de Barros (2018), os antropônimos da Língua Brasileira de Sinais - Libras - atribuídos à autores/pesquisadores, disponíveis no Manuário Acadêmico e Escolar ${ }^{4}$ organizado pelo Colégio de Aplicação e pelo Departamento de Ensino Superior do Instituto Nacional de Educação de Surdos (INES), disponível na aba Dicionário Onomástico.

\section{Estudos Antroponomásticos e as Línguas de Sinais}

Em várias comunidades de línguas de sinais em todo o mundo, a atribuição de um sinal de nome é comum para identificar os sujeitos que fazem parte dessas comunidades: surdos, intérpretes, pessoas ouvintes usuárias das línguas de sinais, pesquisadores da área, dentre outros (PAALES, 2011; BORSTEL, 2017). Entretanto, não apenas esses sujeitos são nomeados, mas também outros que por diferentes motivos precisam ser referenciados, podendo ser celebridades, políticos, reitores de universidades, autores/pesquisadores etc.

Entretanto, o que se percebe é que o momento e a forma como cada um desses grupos de sujeitos são nomeados não acontecem do mesmo modo. Surdos e ouvintes, filhos de pais surdos, por exemplo, geralmente recebem um sinal de nome logo nos primeiros meses de vida, por seus pais. Essa nomeação está muito ligada a um sentimento de pertencimento à comunidade surda ao qual fazem parte. Já os surdos, filhos de pais ouvintes, geralmente recebem seu sinal de nome por seus pares, pois, na grande maioria das vezes, seus pais desconhecem a língua de sinais. De modo geral a comunidade surda chama esse procedimento

\footnotetext{
${ }^{3}$ Nas línguas de sinais não há uma padronização para estes antropônimos. Day e Sutton-Spence (2010); Supalla (1990) e Mindess (1990) utilizam sign name e Paales (2010) chama de personal name signs. No Brasil Sell e Rech (2019) utilizaram a terminologia "sinais de nomes" e Barros (2018) denominou esses signos de "sinaisnome"

${ }^{4}$ Disponível em: http://www.manuario.com.br/dicionario-onomastico . Acesso em: 05 nov. 2019
} 
de "batismo", o qual ocorre no encontro surdo-surdo, que pode acontecer na escola, nas associações de surdos, ou em outro lugar em que as pessoas surdas se encontram.

No caso das pessoas ouvintes participantes da comunidade surda, como professores bilingues, intérpretes de língua de sinais ou pesquisadores, a atribuição de um sinal de nome ocorre, geralmente, no momento em que começam a se envolver efetivamente com a língua de sinais, significando uma inserção nesta comunidade.

Nesses casos, essas pessoas têm ciência de que possuem um sinal de nome que coexiste com seus nomes civis, e sabem a hora em que precisam utilizar um ou o outro. Sabem quando e onde há necessidade de se apresentarem utilizando o sinal de nome ou o nome de registro, bem como quando precisam utilizar os dois nomes juntos. A esse respeito Sell e Rech (2019) afirmam que quando membros que fazem parte da comunidade surda vão realizar uma apresentação pessoal inicial, tendem a utilizar os nomes nas duas línguas, sendo que, mais tarde, utilizam apenas os sinais de nomes, deixando o nome oficial em segundo plano.

Indivíduos que não fazem parte da comunidade surda, como políticos, artistas, jogadores de futebol, autores/pesquisadores, dentre outros, recebem um sinal de nome quando precisam ser referenciados por necessidades diversas. Diferentemente dos indivíduos que fazem parte da comunidade surda, estes, não necessariamente sabem que possuem um sinal de nome que lhes foi atribuído dentro da comunidade surda, pois, segundo Delaporte: "mesmo que os surdos não existam pra você, você existe nos sistema de nomes deles ${ }^{5 \%}$ (DELAPORTE 2002: 2007 apud PAALES, 2011: 49). Há inclusive a atribuição de sinais de nomes a autores/pesquisadores famosos já falecidos, como Descartes, Aristóteles, Lev Vygotsky, Antônio Gramsci etc. Este artigo focará os sinais de nomes atribuídos em Língua Brasileira

\footnotetext{
${ }^{5}$ Tradução nossa
} 
de Sinais a autores consagrados da área de Ciências Humanas e Sociais que são citados em estudos surdos.

Seide afirma que os antropônimos "são fruto de uma escolha por parte do designador, escolha feita de acordo com seus valores e sua visão de mundo, os quais são histórica e socialmente determinados (SEIDE, 2013: 167). Paales (2011), na mesma direção, afirma:

\begin{abstract}
Os sinais de nome representam uma linguagem viável e uma tradição de herança, sua formação e percepção são baseadas em informações visuais, espaço cultural histórico, crenças culturais do grupo e meios de expressão linguísticos. A prática de usar e formar sinais de nome varia de acordo com as comunidades. (PAALES, 2011: 47) [tradução nossa]
\end{abstract}

Sendo assim, é possível afirmar que, do mesmo modo como acontece com as línguas orais, nas línguas de sinais, o processo de nomeação de pessoas não ocorre da mesma forma em todas as diferentes comunidades de línguas de sinais, pois ainda segundo Seide (2013) "cada língua apresenta recursos linguísticos distintos disponíveis para a nomeação e, mais ainda, havendo línguas utilizadas por diversos povos e nações, há uso e recursos linguísticos à disposição do usuário" (SEIDE, 2013: 167).

Alguns pesquisadores já se debruçaram a estudar os sinais de nomes em diversas comunidades de línguas de sinais. O sistema linguístico e cultural de atribuição de sinais de nomes da Língua Americana de Sinais já foi pesquisado por diversos autores em diferentes línguas de sinais. Supalla $(1990,1992)$ e Mindness (1990), Meadow (1997) nos Estados Unidos. Delaporte (1998) França. Na Inglaterra, Rachel Sutton-Spence e Linda Day (2010). Para os sinais de nomes na Suécia, econtra-se Börstell (2017). Já Kourbetis e Hoffmeister (2002), analisam Sinais de Nomes na Língua de Sinais Grega. No caso dos sinais de nome da Língua de Sinais Chinesa foram pesquisados por Yau \& He (1989). Paaples (2010; 2011) para a Língua de Sinais Estoniana. Por fim, no Brasil Barros (2018) apresenta um estudo sobre os sinais de nome da L’ngua Brasileira de Sinais.

Paales (2011) investigou os sinais de nomes de pessoas ouvintes, ligadas ou não às comunidades surdas de vários países como Estônia, Rússia, Finlândia, Alemanha, dentre outros, e os agrupou em três grupos: 1) sinais de nomes atribuídos a pessoas relacionadas a comunidade surda; 2) sinais de nomes destinados a pessoas atribuídos às figuras públicas e 3) sinais de nomes atribuídos a figuras religiosas. As fontes de pesquisas utilizadas foram publicações, informações coletadas com surdos, intérpretes, pesquisadores das línguas de 
sinais e manuscritos. Em suas pesquisas, a pesquisadora percebeu que, os sinais de nomes para pessoas ouvintes são criados e desenvolvidos no interior da comunidade surda, e que, os sinais atribuídos a pessoas internacionalmente conhecidas podem, ou não, variar de acordo com as comunidades de língua de sinais. Em relação a formação linguística, Paales não encontrou diferença entre os sinais atribuídos a surdos e ouvintes (PAALES, 2011:68-69)

Já Barros (2018) propõe uma taxonomia para os antropônimos encontrados na Língua Brasileira de Sinais, a partir de 113 entrevistas realizadas com alunos e professores da Universidade Federal de Goiás, nas quais onde identificou, descreveu e nomeou 4 taxes, 28 subtaxes e 4 infrataxes, conforme quadro abaixo:

Quadro 1 - Taxonomia Antroponímica na Libras

\author{
1.1. Inicialização \\ 1.2. Uma letra \\ 1.3. Mais de uma letra \\ 1.4. Soletração \\ 1.5. Tradução \\ 2. Aspecto Físico (AF)
}

TAXONOMIA ANTROPONÍMICA NA LIBRAS

1. Empréstimo de Língua Oral (ELO)

2.1. Formato do cabelo

2.2. Comprimento do cabelo

2.3. Cor do cabelo

2.4. Formato da testa

2.5. Formato da sobrancelha

2.6. Formato dos cílios

2.7. Formato dos olhos

2.8. Cor dos olhos

2.9. Formato do nariz

2.10. Formato das bochechas

2.11. Formato da boca

2.12. Formato dos dentes

2.13. Formato do queixo

2.14. Presença de sinal

2.15. Cor da pele

2.16. Característica marcante de alguma parte do corpo que não a cabeça

3. Aspecto Comportamental (AC)

3.1. Humor

3.2. Hábito

3.2.1. Vestuário

3.2.2. Acessório

3.2.3. Penteado ou barba/bigode

3.2.4. Tiques

3.3. Atitude

3.4. Habilidades cognitivas

4. Aspecto Social (AS)

4.1. Profissão

4.2. Evento

4.3. Procedência

Fonte: Barros (2018, p. 51) 
Do ponto de vista quantitativo, a análise de Barros (2018) mostrou que a comunidade surda analisada, ao atribuir um sinal de nome, apresenta um sistema em que há uma combinação de taxes e subtaxes. Segundo a autora:

\begin{abstract}
A análise dos dados mostrou que apenas 8 dos 113 sinais-nomes pertencem exclusivamente à taxe Empréstimo de Língua Oral (ELO), dados que se opõem à tendência nos Estados Unidos, relatada por Supalla (1992), de a taxe ELO ser amplamente usada sem estar em combinação com as demais taxes. Sinais-nomes que combinam a taxe ELO e alguma outra taxe são 88 do total de113. Assim, todos os sinais-nomes que utilizam a taxe ELO, sozinha ou em combinação com as demais, representam uma maioria de 96 dos 113 sinais-nomes analisados. Dos sinais-nomes que utilizam a taxe ELO combinada (total de 88), 66 estão combinados à taxe Aspecto Físico (AF), 16 à taxe Aspecto Comportamental (AC), 4 à taxe Aspecto Social (AS) e 2 às taxes $\mathrm{AC}$ e $\mathrm{AF}$ ao mesmo tempo, mostrando uma preferência significativa pela combinação entre as taxes ELO e AF. (BARROS, 2018: 57)
\end{abstract}

Na sessão seguinte, analisamos os dados coletados a partir da proposta pioneira de Barros para a Libras, verificando se essa taxonomia se aplica à na atribuição de sinais de nome atribuídos a autores/pesquisadores do meio acadêmico.

\title{
Metodologia e análise dos dados
}

Para analisar de que forma ocorreu a atribuição de um sinal de nome para autores/pesquisadores, este trabalho utilizou, como base de dados, os sinais que se encontram no Manuário Acadêmico e Escolar organizado pelo Colégio de Aplicação e pelo Departamento de Ensino Superior do Instituto Nacional de Educação de Surdos (INES), disponível na aba Dicionário Onomástico. Segundo Mandelblatt e Favorito (2018) o Manuário tem o seguinte objetivo:

[a] construção de um dicionário terminológico acadêmico multidisciplinar, digital e disponível online, referente aos diferentes campos curriculares que compõem o curso de Pedagogia do DESU/INES e o Colégio de Aplicação do INES (CAP-INES), com entradas e verbetes nas duas línguas: Português e Libras (MANDELBLATT \& FAVORITO, 2018: 165).

Optou-se por essa fonte de dados, pois, para além da escassez de sites voltados para a Onomástica da Língua Brasileira de Sinais, o INES é uma das referências nacionais em organização obras lexicográficas, bem como oferta o Curso Pedagogia Bilíngue, dispondo de 
uma equipe de pesquisadores, estudantes surdos e tradutores e intérpretes de Libras que, desde 2006, com a criação do Curso Bilíngue de Pedagogia, vêm pesquisando e registrando os sinais ligados a linguagem acadêmica da área (MANDELBLATT \& FAVORITO, 2018).

O Dicionário Onomástico é composto por 86 sinais de nomes atribuídos a autores/pesquisadores, dos quais 25 são pesquisadores da área da Libras e/ou educação de surdos e 61 são autores consagrados de diversas áreas das Ciências Humanas, referenciados no Curso de Pedagogia Bilíngue. Partindo do pressuposto de que a forma de nomear essas pessoas não ocorre da mesma forma, esta pesquisa se debruçou a analisar somente o primeiro grupo.

A organização do Dicionário Onomástico foi feita acontece da seguinte forma: do lado esquerdo encontra-se o índice onomástico, organizado em ordem alfabética, e do lado direito, uma coluna que apresenta os verbetes que, ao serem acionados, direcionam o leitor para um vídeo com minibiografias que foram gravadas em formato de programas televisivos (MANDELBLATT \& FAVORITO, 2018), conforme figura 1. Para a análise de cada sinal, as duas colunas foram consultadas, e algumas diferenças foram identificadas, conforme abordaremos mais adiante.

Figura 1 - Visualização do site do Manuário Acadêmico e Escolar

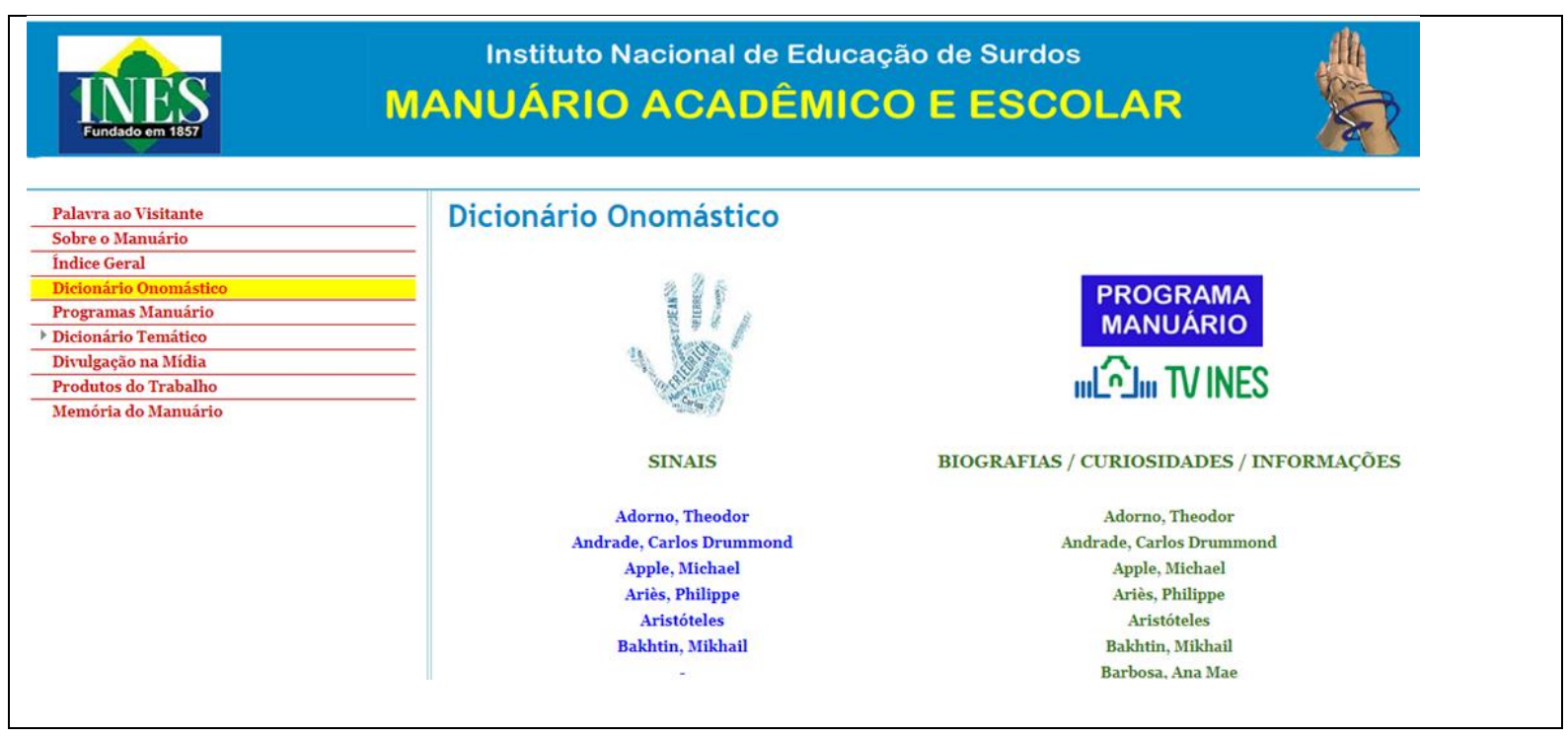


Onomástica Desde América Latina, n.2, v.1, julho - dezembro, 2020, p. 67-82. ISSN 2675-2719

Fonte: http://www.manuario. com.br/dicionario-onomastico ${ }^{6}$

Cabe também registar que, durante a análise dos sinais de nomes encontrados no Manuário, surgiu a necessidade de entrar em contato, via e-mail, com as coordenadoras e responsáveis pelo projeto para dirimir algumas dúvidas quanto à produção de alguns sinais. As principais indagações feitas às pesquisadoras foram: diferença na execução dos sinais que estavam na primeira coluna e no vídeo biográfico, motivações desconhecidas e comprovação de hipóteses para alguns sinais de nomes. Todas as dúvidas foram sanadas prontamente pelas pesquisadoras, e quanto às diferenças entre o que estava na primeira coluna e o que foi produzido nos vídeos biográficos, foi confirmado que o correto é o que estava no índice onomástico encontrado na página do INES.

Inicialmente, visualizamos cada um dos sinais de nomes selecionados, buscando descrevê-los e identificar em qual das taxes e/ou subtaxes propostas por Barros (2019) esse signo melhor se encaixava. Dos 61 sinais de nomes analisados, 56 foram classificados usando a proposta de Barros (conforme tabela 1). Já os demais foram analisados separadamente conforme será abordado mais adiante.

Tabela 1: Quantidade de sinais de nome por taxe

\begin{tabular}{|l|c|}
\hline Taxes & Quantidade de Sinais de nomes \\
\hline ELO & 2 \\
\hline ASPECTO FÍSICO (AF) & 25 \\
\hline ASPECTO COMPORTAMENTAL (AC) & 11 \\
\hline ELO + AF & 8 \\
\hline ELO + AC & 7 \\
\hline AF + AC & 2 \\
\hline AF + AS & 1 \\
\hline TOTAL & 56 \\
\hline
\end{tabular}

Em relação aos sinais de nomes que pertencem exclusivamente à taxe ELO, foi possível identificar que apenas dois sinais de nomes atribuídos a dois autores/pesquisadores.

\footnotetext{
${ }^{6}$ Acesso em 10 de novembro de 2019
} 
Esse resultado assemelha-se às pesquisas de Barros (2018: 17), a qual afirma que "os dados se opõem à tendência dos Estados Unidos, relatada por Supalla (1992), de a taxe ELO ser amplamente usada sem estar em combinações com as demais taxes". Essa diferenciação vai ao encontro da afirmação de Seide (2013: 167) de que recursos linguísticos diferentes são utilizados para nomeação em cada língua.

Outra constatação importante diz respeito aos sinais de nomes que estão relacionados à aparência física. A maioria dos sinais de nomes encontrados no Manuário pertencem exclusivamente à taxe Aspecto Físico. Na pesquisa de Barros (2011), dos 113 sinais de nomes pesquisados, apenas 11 pertenciam exclusivamente à Taxe Aspecto Físico, entretanto 66 pertenciam a taxes ELO e Aspecto físico. Já nas respostas oferecidas pelas pesquisadoras do INES, foi informado que fotos dos autores/pesquisadores foram utilizadas no momento da atribuição dos sinais de nomes. Assim, com base baseado nas duas pesquisas, parece razoável inferir que aspecto físico é um fator motivante para os sinais de nomes, mas quando os sujeitos surdos não têm muitas informações biográficas a respeito dos indivíduos nomeados, e são expostos a imagens, tendem a atribuir sinais de nomes baseados em suas características físicas.

Interessante apontar que é possível verificar que houve quatro associações diferentes de taxes na amostra analisada. Dessas quatro, três apresentam a aparência física, corroborando com o que já foi dito: aparência física foi um fator bem importante na hora de atribuir um sinal de nome. Isso também ocorre com o que Barros (2018) denominou de "aspecto comportamental", pois a subtaxe 3.232 que a autora chamou de "Penteado ou barba/bigode", nos parece mais relacionada à aparência física do que algo relacionado ao comportamento. Nesta subtaxe, foram identificados 8 sinais de nomes atribuídos por causa de fotografias: provavelmente os surdos que criaram o sinal foram conduzidos pela imagem, e não pelo hábito de usar barba. 
Algo que deve ser observado, também, é que, após o advento dos estudos linguísticos a respeito da Língua Brasileira de Sinais, percebe-se um movimento linguístico e político de valorização dessa língua, usando como uma das estratégias o distanciamento do uso da Língua Portuguesa na criação de novos sinais. Neste sentido, é possível que os sinais de nomes criados e coletados pelos pesquisadores possam ter influência desse movimento, o qual evita, por exemplo, utilizar a primeira letra do nome do autor em português para realizar o sinal. De certo, o único modo de comprovar esta hipótese seria realizando um estudo diacrônico da atribuição de sinais de nomes.

Em relação aos sinais de nomes em que não foi possível classificar pela taxe a partir da taxonomia de Barros (2018), duas situações foram identificadas: a primeira, diz respeito a 6 signos que fazem alusão a uma percepção imagética ou "sinestésica" do nome ou sobrenome do autor/pesquisador; a segunda, um sinal de nome composto, em que a segunda taxe não foi possível ser localizada na proposta, as quais serão detalhadas na sequência.

No que diz respeito a uma percepção imagética dos nomes ou sobrenomes, temos os sinais de nomes atribuídos a três autores/pesquisadores: Henry Giroux ${ }^{7}$, Jean-Claude Passeron $^{8}$ e Felix Guattari ${ }^{9}$. Foi observado e comprovado na troca de e-mails com as pesquisadoras que, ao atribuir o sinal de nome a Henry Giroux, no sobrenome Giroux, houve uma identificação com a palavra do português "girar", o que motivou o seu sinal, conforme a Figura (2). Do mesmo modo, com Passeron, que foi associado a palavra do português "passear" (figura 3) e Felix (Felix Guatarri), associado a "feliz". Vale ressaltar, que, para este último, uma característica física também foi usada como motivação, criando um sinal composto, conforme a Figura (4).

Figura 2 - Sinal de nome de Henry Giroux

\footnotetext{
${ }^{7}$ Segundo o Manuário, Henry Giroux é “um dos teóricos fundadores da pedagogia crítica dos Estados Unidos.

${ }^{8}$ Segundo o Manuário, Jean Claude Passeron é um sociólogo francês, considerado neomarxista.

${ }^{9}$ Segundo o Manuário, Félix Guattari foi um psicanalista revolucionário francês.
} 


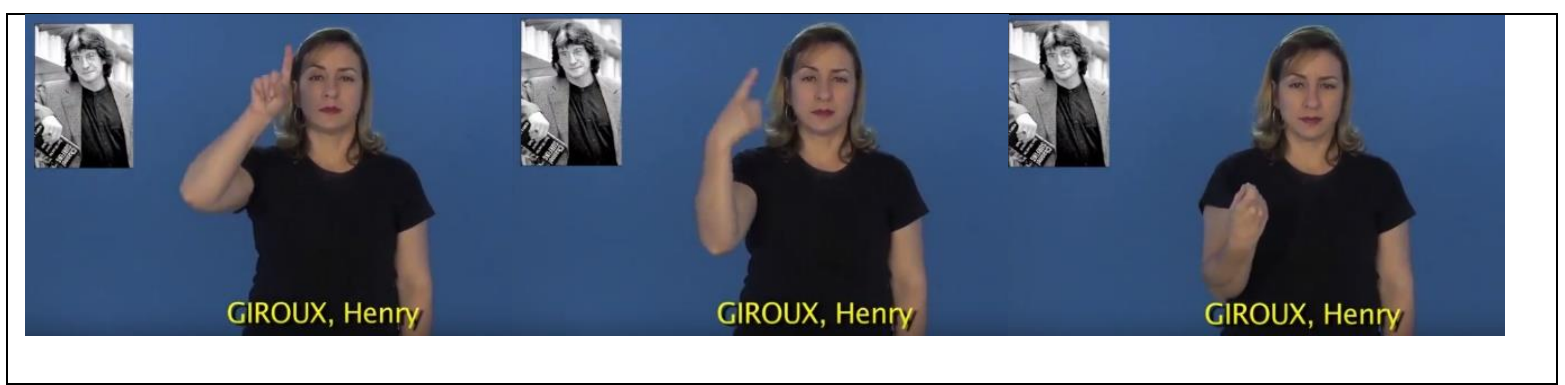

Fonte: Dicionário Onomástico - INES

Figura 2 - Sinal de Nome de Jean-Claude Passeron

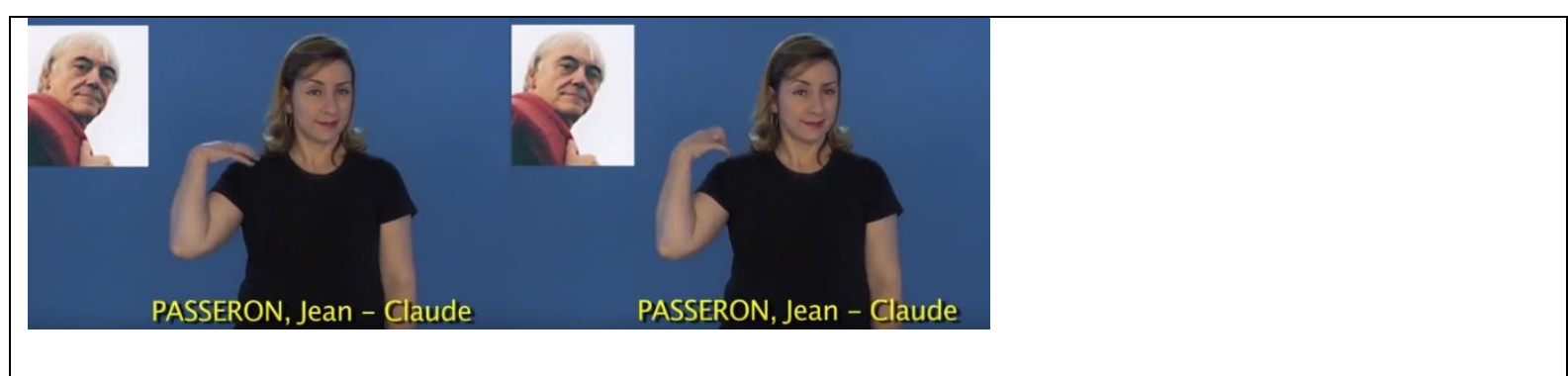

Fonte: Dicionário Onomástico - INES

Figura 3 - Sinal de nome de Felix Guattari

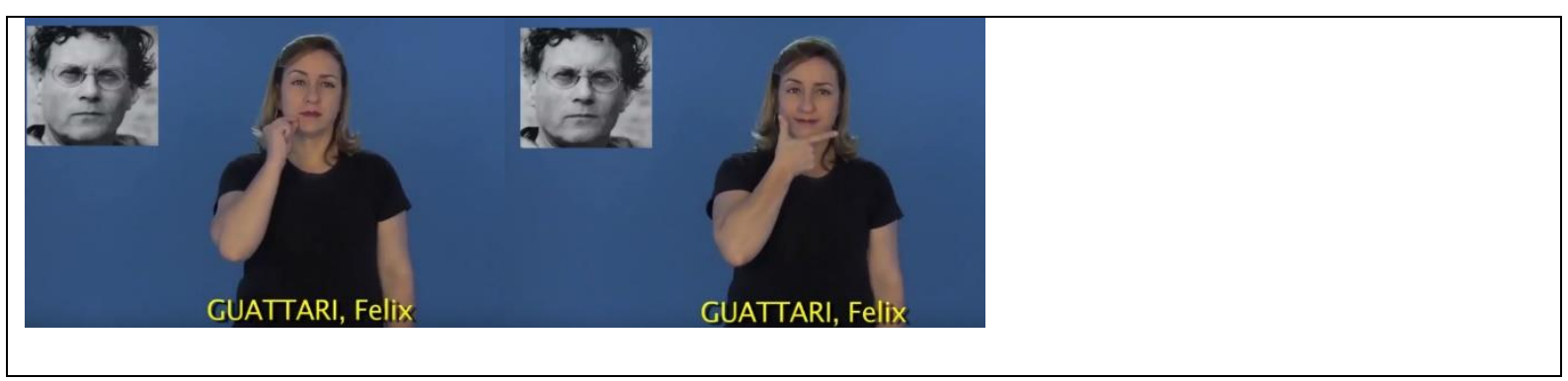

Fonte: Dicionário Onomástico - INES

O sinal de nome que apresenta uma motivação que pode ser relacionado a uma percepção "sinestésica', foi atribuído a Stuart Hall ${ }^{10}$. O sobrenome do autor "Hall”, em virtude da semelhança das palavras, foi relacionado a bala halls, conhecida pelo seu sabor mentolado, forte e ardente. Assim, o sinal de nome faz alusão a um movimento de "esfriamento" da boca, conforme Figura 4.

Figura 4 - Sinal de nome de Stuart Hall

\footnotetext{
${ }^{10}$ De acordo com o Manuário, Stuart Hall foi "um sociólogo jamaicano e um dos principais teóricos do multiculturalismo, que viveu no Reino Unido e foi um dos pioneiros do campo das pesquisa conhecida como "estudos culturais".
} 


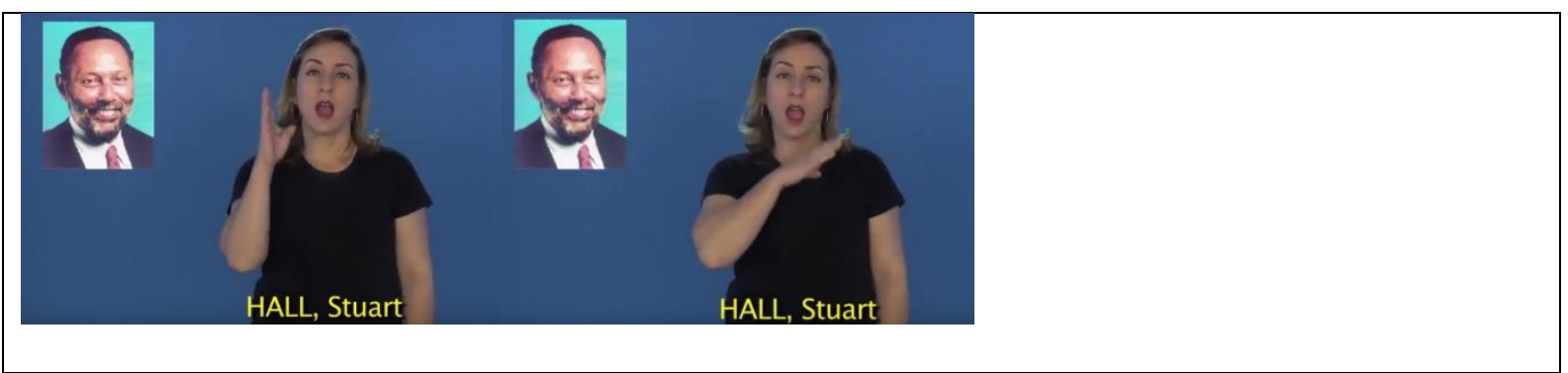

Fonte: Dicionário Onomástico - INES

Os casos apresentados sugerem o uso de algum processo metafórico na criação do sinal, o qual parece estar atrelado a arbitrariedade do signo linguístico. No entanto, uma análise mais detalhada ainda precisa ser realizada a fim de verificar o quanto esse recurso é usual na atribuição de sinais nomes dessa natureza. Uma possibilidade de análise seria comparar esse fenômeno com o que acontece na ambiguidade de segmentação de algumas expressões. Por exemplo, na tradução do sinal de nome da cidade de Sapucaia/RS, o sinal equivalente em Libras reflete essa ambiguidade de segmentação traduzido como SAPOCAIR.

Já sinal de nome atribuído a Charles Chaplin é um sinal composto por duas características marcantes do personagem Carlitos representado pelo referido ator. A saber, o bigode que ele usava, e a alusão ao movimento que ele fazia com o corpo e com a bengala quando se apresentava. A primeira parte está relacionada à Taxe que Barros denominou de Aspecto Comportamental, subtaxe "Penteado ou barba/bigode". Entretanto, o aspecto performático, ou seja, o trejeito de rodar a bengala durante suas aparições, não está presente em nenhuma das taxes e subtaxes propostas por Barros.

Figura 5 - Sinal de nome de Charles Chaplin

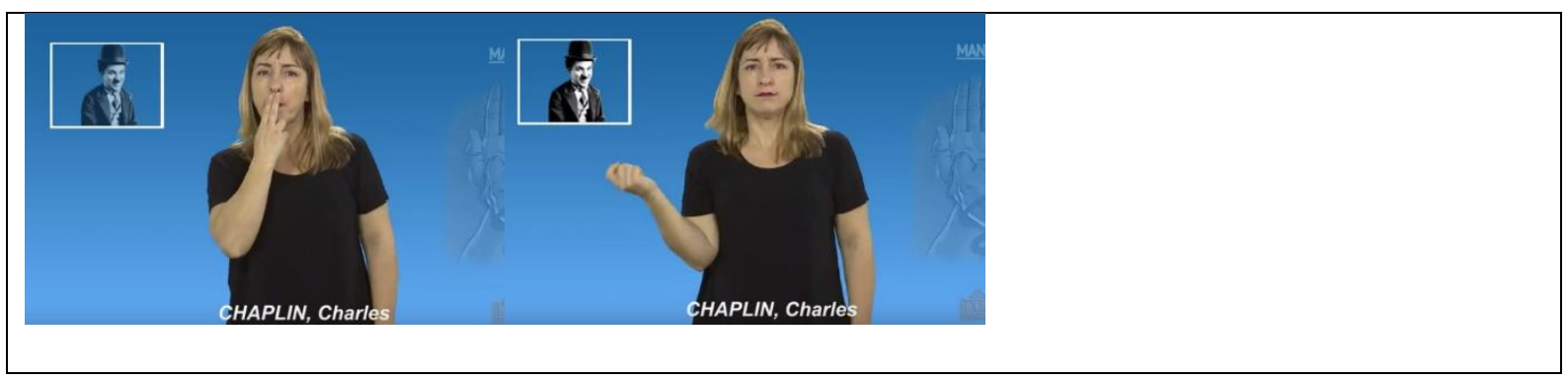


Fonte: Dicionário Onomástico - INES

Na criação desse sinal de nome para Charles Chaplin o que parece se evidenciar é o uso dos chamados Classificadores das Línguas de Sinais, no caso o trejeito do personagem Carlitos, associado ao aspecto comportamental, subtaxe "Penteado ou barba/bigode". Mais uma vez, carece-se de pesquisa e análise de outros sinais de nome com essas características a fim de entender o fenômeno que está por trás da criação desse tipo de sinal de nome.

\section{Considerações Finais}

Este artigo teve como objetivo principal analisar os antropônimos da Libras atribuídos à autores/pesquisadores, disponíveis no Manuário Acadêmico e Escolar ${ }^{11}$ organizado pelo Colégio de Aplicação e pelo Departamento de Ensino Superior do Instituto Nacional de Educação de Surdos (INES), disponível na aba Dicionário Onomástico. Como referencial teórico, foi utilizada a taxonomia desenvolvida por Barros (2018).

A análise apontou que a maioria dos sinais de nome analisados podem ser classificados a partir dos estudos de Barros. No entanto, alguns sinais de nome apresentaram características peculiares que ainda carecem de estudo aprofundado, como no caso de sinais de nome que parecem apresentar Classificadores em sua formação, ou ainda aqueles que apresentam fenômenos envolvendo percepção imagética e, ainda, aqueles que sugerem algum processo metafórico. Tais casos revelam, no mínimo, a necessidade de rever e/ou acrescentar novas classificações à taxonomia proposta, o que aponta para a riqueza desse campo de estudo.

\footnotetext{
${ }^{11}$ Disponível em: http://www.manuario.com.br/dicionario-onomastico . Acesso em: 05 nov. 2019
} 


\section{Referências}

Barros, M. (2018). Taxonomia Antroponímica nas Línguas de Sinais: A motivação dos Sinais-nomes. RE-UNIR, 5, 40-62.

Börstell, C. (2017). Types and Trends of Name Signs in the Swedish Sign Language Community. SKY Journal of Linguistics 30, 7-34.

Day, L., Sutton-Spence, R. (2010). British sign name customs. Sign Language Studies 11, 2254.

Delaporte, Y. (1998). Des noms silencieux. Le système anthroponymique des sourds français. L'Homme, tome 38 146, 7-45.

Dick, M. V. de P. do A. (1992). Toponímia e Antroponímia no Brasil. Coletânea de Estudos. São Paulo: FFLCH.

Kourbetis, V., Hoffmeister, R. J. (2002). Name signs in Greek Sign Language. American Annals of the Deaf 147, 35-43.

Mandelblatt, J. Favorito, W. (2018). A Expansão e o registro do léxico terminológico em Libras: a contribuição do Manuário Acadêmico do INES. Revista Espaço 49, 153 - 172.

Meadow, K. P. (1977). Name signs as identity symbols in the Deaf community. Sign Language Studies 16, 237-246.

Mindess, A. (1990). What name signs can tell us about Deaf culture. Sign Language Studies 66, $1-23$.

Paales, L. (2011). Name signs for hearing people. Folklore 47, 43-76.

Seabra, M. C., Isquerdo, A. N. (2018). A onomástica em diferentes perspectivas: resultados de pesquisas. Revista de Estudos da Linguagem 3, 993-1000.

Seel, F. S. F., Rech, G. C. R. (2019). Os sinais de nome na Língua Brasileira de Sinais. In: Anais do I Congresso Internacional de Lexicologia, Lexicografia, Terminologia e Terminografia das Línguas de Sinais e II Fórum Internacional sobre Produção de Glossários e Dicionários em Línguas de Sinais, Brasília, Distrito Federal, Brasil.

Seide, M. S. (2013). Toponomástica e antroponomástica: paradigma e métodos. Confluência Revista do Instituto de Língua Portuguesa, 44 e 45, 165-184.

Souza, I.L., Gediel, A.L. (2017). Os sinais dos Surdos: Uma análise a partir de uma perspectiva cultural. Trab. Ling. Aplic, Campinas 56, 163- 185.

Supalla, S. J. (1990). The arbitrary name sign system in American Sign Language. Sign Language Studies 67, 99-126.

TV INES. Manuário: Jean Claude Passeron. 2016. Disponível em: http://tvines.org.br/?p=12240. Acesso em 5 maio 2020. 
Onomástica Desde América Latina, n.2, v.1, julho - dezembro, 2020, p. 67-82. ISSN 2675-2719

TV INES. Manuário: Félix Guattari. 2015. Disponível em: http://tvines.org.br/?p=11089. Acesso em 5 maio 2020.

TV INES. Manuário: Stuart Hall. 2015. Disponível em: http://tvines.org.br/?p=10278. Acesso em 5 maio 2020.

TV INES. Manuário: Giroux. 2014. Disponível em: http://tvines.org.br/?p=5898. Acesso 5 maio 2020.

Yau, S., He, J. (1989). How Deaf children in a Chinese school get their sign names. Sign Language Studies 18, 305-322. 